Article

\title{
Toward Overcoming the Challenges in the Comparison of Different Pd Nanocatalysts: Case Study of the Ethanol Oxidation Reaction
}

\author{
Oliver Asger Hjortshøj Schreyer ${ }^{\dagger}$, Jonathan Quinson ${ }^{*}+\underset{+}{+}$ and María Escudero-Escribano *(i) \\ Department of Chemistry, University of Copenhagen, 5 Universitetsparken, 2100 Copenhagen, Denmark; \\ oliver-hs@hotmail.com \\ * Correspondence: jonathan.quinson@chem.ku.dk (J.Q.); maria.escudero@chem.ku.dk (M.E.-E.) \\ + These authors contributed equally.
}

Received: 8 October 2020; Accepted: 23 October 2020; Published: 28 October 2020

check for updates

\begin{abstract}
Precious metal nanoparticles, in particular palladium nanomaterials, show excellent catalytic properties and are key in the development of energy systems. For instance, ethanol fuel cells are promising devices for sustainable energy conversion, where Pd-based catalysts are key catalysts for the related ethanol oxidation reaction (EOR). Pd is a limited resource; thus, a remaining challenge is the development of efficient and stable Pd-based catalysts. This calls for a deeper understanding of the Pd properties at the nanoscale. This knowledge can be gained in comparative studies of different Pd nanomaterials. However, such studies remain challenging to perform and interpret due to the lack of cross-studies using the same Pd nanomaterials as a reference. Here, as-prepared sub $3 \mathrm{~nm}$ diameter surfactant-free Pd nanoparticles supported on carbon are obtained by a simple approach. The as-prepared catalysts with Pd loading 10 and $30 \mathrm{wt} \%$ show higher activity and stability compared to commercially available counterparts for the EOR. Upon electrochemical testing, a significant size increase and loss of electrochemical active surface are observed for the as-prepared catalysts, whereas the commercial samples show an increase in the electrochemically active surface area and moderate size increase. This study shines light on the challenging comparison of different catalysts across the literature. Further advancement in Pd (electro)catalyst design will gain from including self-prepared catalysts. The simple synthesis detailed easily leads to suitable nanoparticles to be used as a reference for more systematic comparative studies of Pd catalysts across the literature.
\end{abstract}

Keywords: palladium; nanoparticles; ethanol oxidation; energy conversion; benchmarking

\section{Introduction}

Precious metals (PMs) are key materials in a wide range of applications such as chemical production [1], energy conversion [2-4], automotive applications [5], medicine [6,7], air [8], or water treatment [9]. Their scarcity requires an optimized use of the limited resources [10]. Nanoscale design of precious metal catalysts is a promising way to make the most of these resources down to the atomic scale. Popular synthesis methods for the research and development of nanomaterials, and in particular nanoparticles (NPs), are often based on wet-chemistry and colloidal syntheses [11]. In this approach, a molecular precursor comprising one or few atoms of PM in an oxidized state is converted to metallic material in the presence of a reducing agent [12]. The latter approach suffers from the drawback of often requiring surfactants to control the size and/or shape of the nanomaterials and to be performed in high boiling point solvents. These features can be detrimental to the catalytic properties of the material, since surfactant can block the active surface. Impurities in the surfactant may lead to less controlled syntheses $[13,14]$. Post-synthesis processing to remove the surfactants, for instance 
with harsh and/or energy-intensive cleaning procedures, may add steps in the synthesis and reduce reproducibility [15-18]. Obtaining small size NPs without surfactant is not a trivial achievement $[19,20]$. We recently addressed the related challenges by developing a simple synthesis of surfactant-free sub $3 \mathrm{~nm}$ Pd NPs on carbon support materials at room temperature in alkaline methanol [21]. This method opens a range of new opportunities that are further exploited here.

Among many applications [22], Pd is a key catalyst for energy conversion in order to propose alternatives to fossil fuel-based energy. Low-temperature fuel cell technologies in particular make it possible to retrieve electricity from environmentally friendly electrochemical processes. Pd NPs show promising activity for electrocatalytic reactions such as the ethanol oxidation reaction (EOR) occurring at the anode of direct ethanol fuel cells (DEFCs) [23-25], as summarized in Equation (1) below for alkaline conditions. During EOR, up to 12 electrons can be retrieved from ethanol, while producing $\mathrm{CO}_{2}$. Another important reaction for energy conversion is the oxygen reduction reaction (ORR) [26] occurring at the cathode of DEFCs that requires electrons to convert $\mathrm{O}_{2}$ to water or hydroxides anions, as detailed in Equation (2). If the EOR is performed at an anode and the ORR is performed at a cathode, chemical energy can be converted into electricity in DEFCs [27], according to Equation (3) [28]:

$$
\begin{gathered}
\text { Anode (EOR) } \mathrm{CH}_{3} \mathrm{CH}_{2} \mathrm{OH}+12 \mathrm{HO}^{-}=>2 \mathrm{CO}_{2}+9 \mathrm{H}_{2} \mathrm{O}+12 \mathrm{e}^{-} \quad \mathrm{E}_{\mathrm{a}}^{0}=-0.74 \mathrm{~V} \\
\text { Cathode (ORR) } 3 \mathrm{O}_{2}+6 \mathrm{H}_{2} \mathrm{O}+12 \mathrm{e}^{-}=>12 \mathrm{HO}^{-} \quad \mathrm{E}_{\mathrm{C}}{ }^{0}=+0.40 \mathrm{~V} \\
\text { Overall reaction } \quad \mathrm{CH}_{3} \mathrm{CH}_{2} \mathrm{OH}+3 \mathrm{O}_{2}=>2 \mathrm{CO}_{2}+3 \mathrm{H}_{2} \mathrm{O} \quad \mathrm{E}^{0}=+1.14 \mathrm{~V} .
\end{gathered}
$$

The main alternative fuel-cell technologies to DEFCs use hydrogen, methanol, or formic acid as fuel to generate electricity. While water is the waste product in hydrogen fuel cells, $\mathrm{CO}_{2}$ is typically the waste product in methanol and formic acid fuel cells. Each technology certainly has its own pros and cons [28]. Briefly, DEFCs offer over alternative technologies the combined benefits of relatively cheap fuel supply from various renewable sources, already existing infrastructures for large-scale production of the fuel, simple storage and transportation, low toxicity, and high energy density [28-30]. Therefore, DEFCS are expected to provide sustainable and affordable energy supply for both transport and stationary applications [31].

Limitations in DEFCs come from the complexity of the EOR. Typically, ethanol is not converted to $\mathrm{CO}_{2}$ by full 12-electron oxidation but rather to products such as acetaldehyde (two-electron oxidation) or acetic acid (four-electron oxidation) in acidic conditions or acetate (four-electron oxidation) in alkaline conditions [28]. This relates to the challenge to break the $\mathrm{C}-\mathrm{C}$ bond to perform the complete oxidation of ethanol to $\mathrm{CO}_{2}$. This means that less than 12 electrons are typically retrieved, and the kinetics of the EOR are slow. One option to optimize DEFCs is to perform the reaction under alkaline conditions where both the EOR and ORR show faster kinetics. The four-electrons oxidation to acetate in alkaline conditions (rather than a mixture of acetic acid and acetaldehyde in acid) means a better Faradic efficiency (conversion of chemical to electricity) up to $66.7 \%$ compared to the full oxidation to $\mathrm{CO}_{2}$. Nevertheless, most systems still remain in a Faradic efficiency range of 37-54\% [28].

To improve the performance of DEFCs, better design of the overall devices and especially the catalysts for the EOR are key. With the improvement of anion-exchange membranes [32], alkaline DEFCs are at the forefront of recent development for lower cost energy devices [33]. A range of catalysts have been explored for the EOR, and the most effective catalyst remained based on precious metals such as $\mathrm{Pt}$ and $\mathrm{Pd}[24,28,34]$. Pd nanocatalysts are more active than $\mathrm{Pt}$ in alkaline media, leading to higher current densities and smaller overpotentials. Therefore, Pt-based catalysts are preferred in acidic and $\mathrm{Pd}$ in alkaline conditions [33]. As a result, a range of $\mathrm{Pd}$ and Pd-based catalysts have been investigated such as PdNi, PdAg, PdAu, PdCo, PdSn, PdRu, and PdZn on various support materials $[24,35]$.

To advance our understanding of catalytic systems and rationally develop improved catalysts, a deeper understanding is needed on how the entangled relationships between synthesis, NP size, nature of support, protocol, and testing conditions affects the catalytic properties [36,37]. It is generally important for further understanding and benchmarking to be able to compare the many different 
materials that are proposed and screened as catalysts to well-established "standard" or "commercially available" catalysts [38]. We detail how our surfactant-free synthesis method can be a simple tool to perform such studies with the example of the EOR. In our previous work, we observed that the sub $3 \mathrm{~nm}$ NPs were subject to a significant size increase upon electrocatalytic characterization and testing [21]. We here further characterize the NPs after electrocatalytic testing. We also benchmark our as-prepared NPs with two commercially available catalysts with $10 \mathrm{wt} \%$ and $30 \mathrm{wt} \% \mathrm{Pd}$ loading on carbon. The approach proposed and the results obtained provide guidelines and tools to optimize $\mathrm{Pd}$ catalyst design and studies. The NP catalyst here simply obtained at room temperature are promising candidates as cross-studies reference materials to better compare various Pd-based catalysts developed for various electrochemical reactions.

\section{Results}

\subsection{As-Synthesised Pd Nanoparticles}

To develop electrodes for the EOR, Pd catalysts are typically supported with different Pd loading on conductive materials such as carbon. The synthesis of Pd NPs supported on Vulcan (Vx) carbon material with a nominal loading of 10 and $30 \mathrm{wt} \%(\mathrm{Pd} / \mathrm{Vx})$ is detailed in the Materials and Methods Section. Transmission electron microscope (TEM) micrographs of the as-prepared samples are reported in Figure 1 together with TEM micrographs of the commercial catalysts. The TEM micrographs analysis confirms that the as-prepared $\mathrm{Pd} / \mathrm{Vx}$ have diameters before electrochemical testing $\left(d_{\text {before }}\right)$ below $3 \mathrm{~nm}$ : $2.1 \pm 0.7 \mathrm{~nm}$ for $10 \mathrm{wt} \%$ (referred to as $\mathrm{Pd} / \mathrm{Vx} 10 \mathrm{wt} \%$ ) and $2.5 \pm 0.9 \mathrm{~nm}$ for $30 \mathrm{wt} \%$ (referred to as $\mathrm{Pd} / \mathrm{Vx} 30 \mathrm{wt} \%)$. The NPs are well distributed over the carbon surface. Inductively coupled plasma mass spectrometry (ICP-MS) measurements suggest a loading of $8.9 \mathrm{wt} \%$ for the sample Pd/Vx $10 \mathrm{wt} \%$ and $26.7 \mathrm{wt} \%$ for $\mathrm{Pd} / \mathrm{Vx} 30 \mathrm{wt} \%$. It is also confirmed that the commercial samples (Pd/C) show a much larger size, $5.5 \pm 1.7 \mathrm{~nm}$ for $10 \mathrm{wt} \%$ (referred to as $\mathrm{Pd} / \mathrm{C} 10 \mathrm{wt} \%$ ) and $5.7 \pm 1.7 \mathrm{~nm}$ for $30 \mathrm{wt} \%$ (referred to as $\mathrm{Pd} / \mathrm{C} 30 \mathrm{wt} \%$ ). The ICP-MS results suggest a loading of $9.5 \mathrm{wt} \%$ for the commercial sample $\mathrm{Pd} / \mathrm{C} 10 \mathrm{wt} \%$ and $30.4 \mathrm{wt} \%$ for $\mathrm{Pd} / \mathrm{C} 30 \mathrm{wt} \%$. The commercial sample shows a more pronounced agglomeration of the NPs. The related size distribution histograms can be found in Figure S1, and the results are also summarized in Table 1 discussed later.

Due to the strong structure-properties relationships at the nanoscale, the different size and distribution on the support are expected to have an impact on the catalytic performances of the NPs. The electrochemically characterization of the NPs was first performed by measuring the NP electrochemically active surface area (ECSA). Please see details in Materials and Methods Section for the electrochemical characterization protocols. The as-prepared $\mathrm{Pd} / \mathrm{Vx} 10 \mathrm{wt} \%$ and $30 \mathrm{wt} \%$ are characterized by ECSA values of $39 \mathrm{~m}^{2} \cdot \mathrm{g}^{-1}$ and $69 \mathrm{~m}^{2} \cdot \mathrm{g}^{-1}$, respectively. The commercial samples are characterized by lower ECSA values of $8 \mathrm{~m}^{2} \cdot \mathrm{g}^{-1}$ and $18 \mathrm{~m}^{2} \cdot \mathrm{g}^{-1}$ for $\mathrm{Pd} / \mathrm{C} 10 \mathrm{wt} \%$ and $30 \mathrm{wt} \%$, respectively, which is consistent with the larger size of the NPs for the commercial samples. The difference between samples with different metal loading for both the as-prepared and commercial catalysts is at first surprising. The loading should not affect the ECSA evaluation, since the ECSA should only depend on the surface available and therefore diameter of the NPs. Then, ECSAs are expected to decrease for a NP size increase. The estimation of lower ECSA for the lowest NP loading can be inferred to the choice to deposit the same mass of $\mathrm{Pd}$ for measurements, which means higher catalysts (Pd + carbon) on the electrode. This higher quantity can result in different film thickness on the electrode. This leads to different capacitance measured during cyclic voltammetry (CV), as shown in Figure S2a. The ECSA was evaluated by measuring the charge related to the reduction of the Pd oxide peak (see Materials and Methods Section). With a higher film thickness, a higher capacitance is observed, and this peak is more challenging to identify. The higher capacitance ultimately accounts for the discrepancy observed for ECSA estimation. In addition, results from our previous work estimated the ECSA around $92 \mathrm{~m}^{2} \cdot \mathrm{g}^{-1}$ for a loading of $50 \mathrm{wt} \%$, which confirms the trend observed here of a higher ECSA estimated with 
higher Pd loading [21]. Nevertheless, these ECSA values remain in the higher range of reported values for monometallic Pd catalysts more typically in the range $10-60 \mathrm{~m}^{2} \cdot \mathrm{g}^{-1}[21,39-45]$.
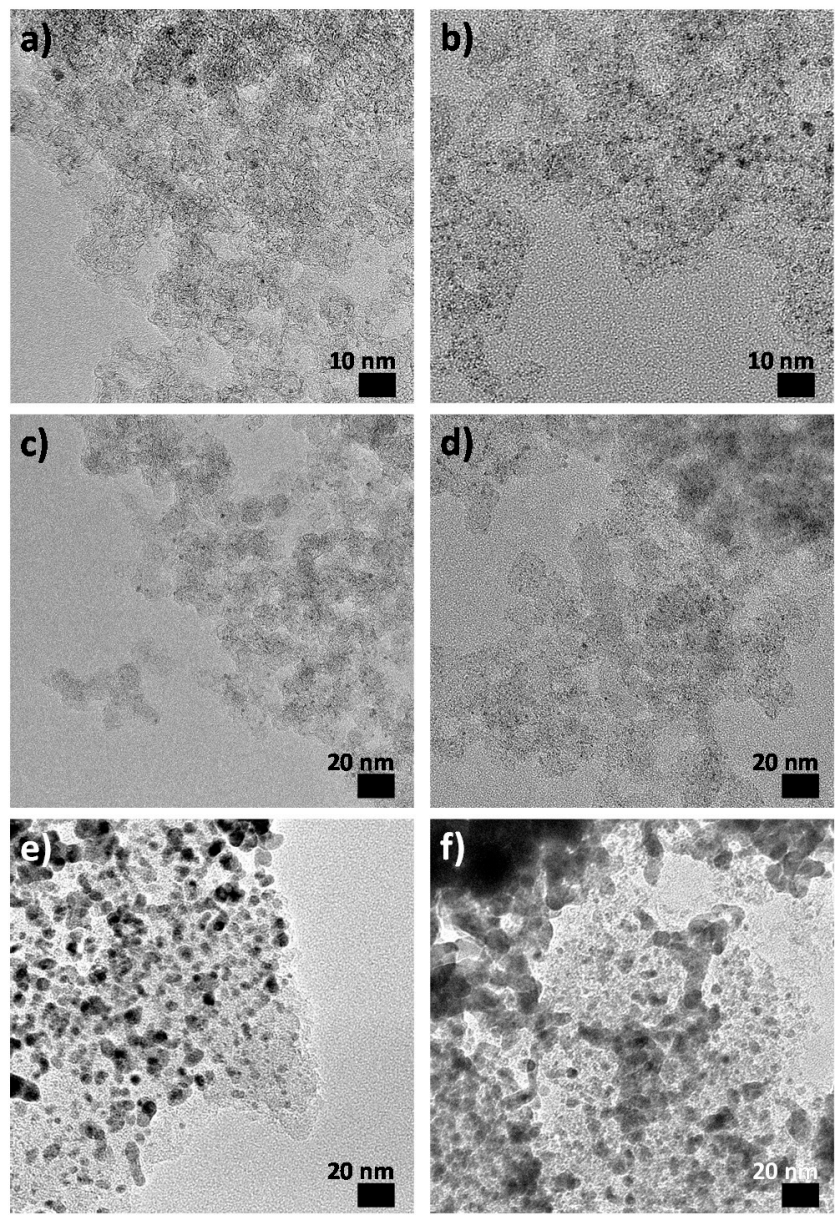

Figure 1. TEM micrographs at different magnifications of (a-d) as-prepared $\mathrm{Pd} / \mathrm{Vx}(\mathbf{a}, \mathbf{c}) 10 \mathrm{wt} \%$ and (b,d) $30 \mathrm{wt} \%$ and commercially available Pd/C (e) $10 \mathrm{wt} \%$ and (f) $30 \mathrm{wt} \%$. See also Figure S1a,b for an enlarged version of Figure $1 \mathrm{a}, \mathrm{b}$.

Table 1. Characterization of the Pd catalysts.

\begin{tabular}{ccccc}
\hline Characteristic & \multicolumn{2}{c}{ Commercial } & \multicolumn{2}{c}{ Synthesized } \\
\hline wt $\%$ & 10 & 30 & 10 & 30 \\
$d_{\text {before}} / \mathrm{nm}$ & $5.5 \pm 1.7$ & $5.7 \pm 1.7$ & $2.1 \pm 0.7$ & $2.5 \pm 0.9$ \\
$d_{\text {after }} / \mathrm{nm}$ & $7.2 \pm 2.7^{*}$ & $7.7 \pm 2.8^{*}$ & $5.5 \pm 1.9$ & $5.7 \pm 1.6$ \\
$\mathrm{MA} / \mathrm{A} \cdot \mathrm{g}^{-1}$ after $1 \mathrm{~h} \mathrm{CA}$ & $28.1 \pm 11.8$ & $60.6 \pm 31.8$ & $91.5 \pm 76.9$ & $121.0 \pm 63.7$ \\
ECSA before EOR $/ \mathrm{m}^{2} \cdot \mathrm{g}^{-1}$ & $8.3 \pm 2.7$ & $17.7 \pm 9.0$ & $38.6 \pm 23.1$ & $68.9 \pm 25.1$ \\
ECSA after EOR $/ \mathrm{m}^{2} \cdot \mathrm{g}^{-1}$ & $22.1 \pm 7.2$ & $20.8 \pm 7.0$ & $23.1 \pm 12.4$ & $33.1 \pm 9.7$ \\
$\mathrm{SA}$ after EOR $/ \mathrm{A} \cdot \mathrm{m}_{\mathrm{Pd}}{ }^{-2}$ & $1.5 \pm 0.9$ & $2.9 \pm 1.2$ & $4.2 \pm 2.3$ & $3.6 \pm 1.6$ \\
\hline
\end{tabular}

* It is actually challenging to identify individual nanoparticles (NPs) after electrochemistry. Note: The large deviation obtained for electrochemical measurements comes from the fact that the average was made for different ink compositions and quantity of material used on the electrode: $3.33 \mu \mathrm{g}$ or $10 \mu \mathrm{g}$ nominal mass of Pd for a total of experiments: 9 for $10 \mathrm{Pd} / \mathrm{C} \mathrm{wt} \%, 10$ for $\mathrm{Pd} / \mathrm{C} 30 \mathrm{wt} \%, 11$ for $10 \mathrm{wt} \% \mathrm{Pd} / \mathrm{Vx}$ and 12 for $30 \mathrm{wt} \% \mathrm{Pd} / \mathrm{Vx}$, see Tables S1 and S2. 


\subsection{Ethanol Oxidation}

\subsubsection{Activity}

The activity of the electrocatalysts was first assessed by cyclic voltammetry (CV) for the EOR in $1 \mathrm{M} \mathrm{KOH}$ alkaline conditions with $1 \mathrm{M}$ ethanol. The typical shape of the cyclic voltammograms for $\mathrm{Pd}$ nanocatalysts is obtained for all samples: Pd/Vx 10 or $30 \mathrm{wt} \%$ and commercially available Pd/C 10 or $30 \mathrm{wt} \%$; see Figure 2. An oxidation peak around $0.8 \mathrm{~V}$ vs. relative hydrogen electrode (RHE) and corresponding to the oxidation of ethanol on the Pd surface is obtained in the forward scan (from low to high potentials, oxidation). The expected products of this oxidation are acetaldehyde and acetate in alkaline conditions as well as possible other oxidation products as summarized in Equations (4) and (5) [30].

$$
\begin{gathered}
\mathrm{CH}_{3} \mathrm{CH}_{2} \mathrm{OH}+5 \mathrm{HO}^{-}=>\mathrm{CH}_{3} \mathrm{CHO}+2 \mathrm{e}^{-}+2 \mathrm{H}_{2} \mathrm{O}+3 \mathrm{HO}^{-}=>\mathrm{CH}_{3} \mathrm{COO}^{-}+4 \mathrm{e}^{-}+4 \mathrm{H}_{2} \mathrm{O} \\
\mathrm{CH}_{3} \mathrm{CH}_{2} \mathrm{OH}+12 \mathrm{HO}^{-}=>\left[\mathrm{CH}_{x}+\mathrm{CO}\right]=>2 \mathrm{CO}_{2}+9 \mathrm{H}_{2} \mathrm{O}+12 \mathrm{e}^{-}
\end{gathered}
$$
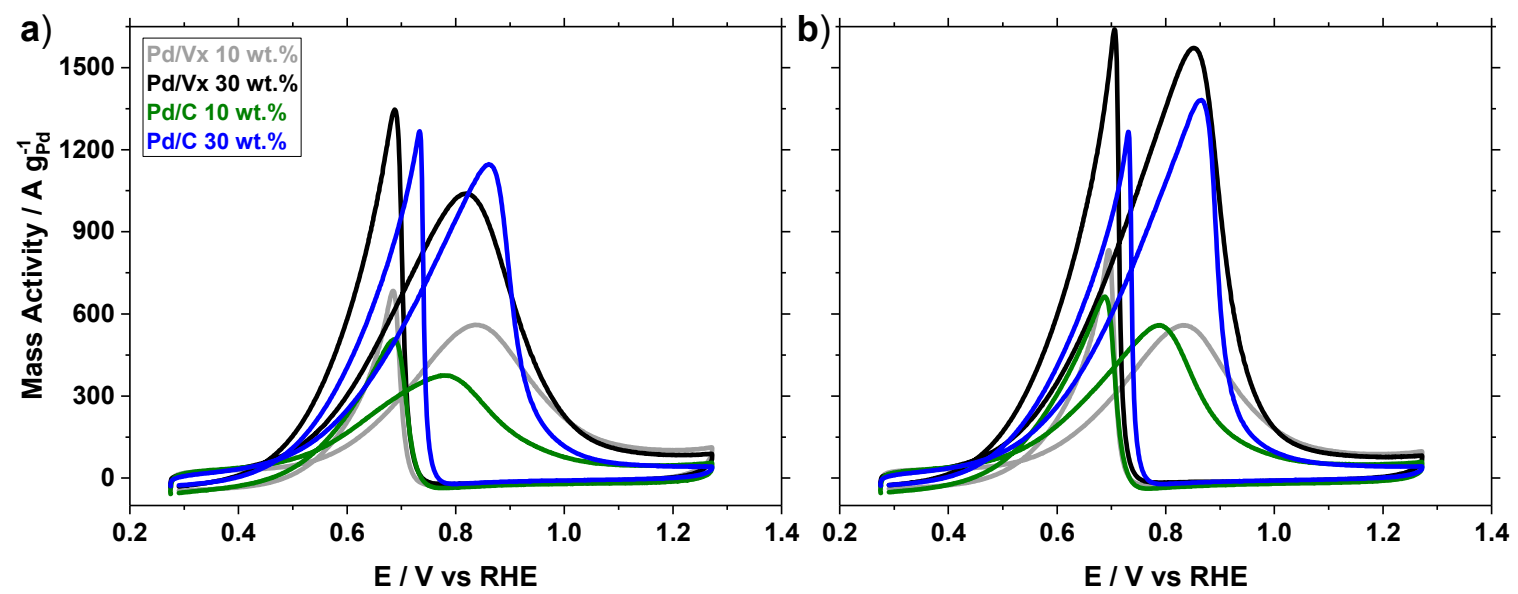

Figure 2. Cyclic voltammograms of Pd NPs supported on carbon as indicated (a) before and (b) after chronoamperometry experiment at $0.71 \mathrm{~V}$ vs. relative hydrogen electrode (RHE) for $3600 \mathrm{~s}$ in $1 \mathrm{M}$ ethanol in $1 \mathrm{M} \mathrm{KOH}$ for the samples as indicated. The 10th scan is reported. The scan rate was $50 \mathrm{mV} \cdot \mathrm{s}^{-1}$. All experiments were performed using argon bubbled in the solution without rotation of the electrode in $1 \mathrm{M}$ ethanol in $1 \mathrm{M} \mathrm{KOH}$. The nominal Pd loading on the electrode is $9 \mu \mathrm{g}$.

At higher potentials, the current drops due to the formation of catalytically inactive Pd oxide [30]. A second oxidation peak around $0.7 \mathrm{~V}$ vs. RHE is obtained on the backward scans (from high to low potentials, reduction). This second peak corresponds to the removal of residual carbon species generated on the Pd surface during the forward scan [30,46-48]. Ethanol oxidation is made possible on this backward scan due to the recovery of active Pd while Pd oxide, which is formed during the forward scan, becoming reduced [30]. A higher mass activity for the oxidation peak around $0.8 \mathrm{~V}$ vs. RHE is indicative of a high activity of the catalyst for the EOR. The catalysts with the higher mass activities are those prepared at $30 \mathrm{wt} \% \mathrm{Pd}$. This is consistent with their higher ECSA, which indicates that the catalysts have a higher surface per mass unit available to perform the EOR. The catalysts with lowest activity are $10 \mathrm{wt} \% \mathrm{Pd} / \mathrm{C}$ NPs.

These results highlight a first challenge in comparing different materials. In the approach used here to characterize the catalysts (see Materials and Methods Section), two choices can be made. Catalysts can be tested using a protocol where the same mass of supported catalysts (Pd + carbon) or the same mass of active material (Pd) is used. Comparing the same mass of Pd for $10 \mathrm{wt} \%$ or $30 \mathrm{wt} \%$ means that the thickness of the film made of $\mathrm{Pd}$ and carbon on the electrode tips will differ and is thicker for $10 \mathrm{wt} \%$ catalyst. If the catalysts were truly comparable, the mass activity of the commercial 
$\mathrm{Pd} / \mathrm{C} 10$ and 30 wt \% should be the same, which is clearly not the case. Therefore, measurements were performed so that the mass of the catalyst (Pd + carbon) was the same. Then, it was also observed that the commercial Pd/C 10 wt \% is giving lower mass activity. These results highlight the difficulty in comparing catalysts from different sources: even commercial benchmark materials may be prepared in different ways. The knowledge on the preparation and treatments that can ultimately affect the catalyst is rarely available, which complicates the interpretation of the results. In this respect, the possibility to simply develop home-made catalysts can render a comparison more systematic, since there is more control on the preparation of the material. A simple one-step preparation method such as the room temperature synthesis used here makes it extremely simple to prepare in a reproducible way such reference materials [21].

For all samples, as CV was performed, an increase in the current was observed in consecutive cyclic voltammograms. This can be explained by an increase in mass activity after electrochemical conditioning. These results are consistent with other reports [43], and it took multiple scans to reach a relative steady state (see Figure S3). To compare the catalysts under the same protocol, the number of scans was set to 10 . The increase in mass activity was in particular pronounced for the $30 \mathrm{wt} \%$ catalysts, which typically showed the highest mass activity. For similar testing conditions and evaluation of the activity by $\mathrm{CV}$, the mass activities reported in the literature vary between ca. 300 and $1300 \mathrm{~A} \cdot \mathrm{g}^{-1}$ [21]. This means that the catalysts considered here show a reasonably high activity. In particular, the catalysts with $30 \mathrm{wt} \%$ show activities in the range of $1000-1500 \mathrm{~A} \cdot \mathrm{g}^{-1}$.

\subsubsection{Stability}

It is a common drawback of Pd catalysts to show an activity decrease over time. This apparent loss of activity is attributed to poisoning of the surface by decomposition products of ethanol such as adsorbed CO $[49,50]$. Addressing the stability of catalysts and understanding the possible reason(s) for this activity loss is an increasing need to improve DEFCs [30]. To test the stability of the catalyst, i.e., how well the mass activity is maintained over time, chronoamperometry (CA) experiments were performed. For such experiments, the activity of the catalysts was measured over time, maintaining the electrode potential of $0.71 \mathrm{~V}$ vs. RHE for $3600 \mathrm{~s}$ in $1 \mathrm{M}$ ethanol in $1 \mathrm{M} \mathrm{KOH}$. The related results are reported in Figure 3. For all catalysts, the mass activity decreases over time. By cross-comparing the catalysts, the commercial Pd/C $10 \mathrm{wt} \%$ shows overall the lowest mass activity, which is consistent with the activity results commented in the previous section and obtained from CV measurements. In comparison, the Pd/Vx $10 \mathrm{wt} \%$ showed a higher mass activity. The commercial $30 \mathrm{wt} \%$ showed the highest mass activity, which is consistent with the higher activity observed in CV measurements detailed in the previous section. Interestingly, Pd/C $30 \mathrm{wt} \%$ initially shows high mass activity. However, for prolonged testing (>600 s), both as-synthesized Pd/Vx $10 \mathrm{wt} \%$ and $30 \mathrm{wt} \%$ catalysts maintain a higher mass activity. It can be concluded that these two prepared catalysts have higher stability than $\mathrm{Pd} / \mathrm{C} 30$ wt \%.

These results stress the difficulty in comparing catalysts from different sources (e.g., synthesized vs. commercial). With little knowledge on the history of the commercial catalyst (e.g., synthesis protocol, conditioning, storage, post-treatments such as heat treatment or cleaning etc.), it is not straightforward to rationalize the faster decrease in activity of the commercial catalyst vs. synthesized catalysts. Overall, the as-prepared catalysts maintained a relatively high activity $>100 \mathrm{~mA} \cdot \mathrm{mg}^{-1}$ after $3600 \mathrm{~s}$ of chronoamperometry compared to most reported Pd catalysts that usually show a mass activity below $100 \mathrm{~mA} \cdot \mathrm{mg}^{-1}$ already after $1800 \mathrm{~s}$ of chronoamperometry $[41,43,45,49]$. 


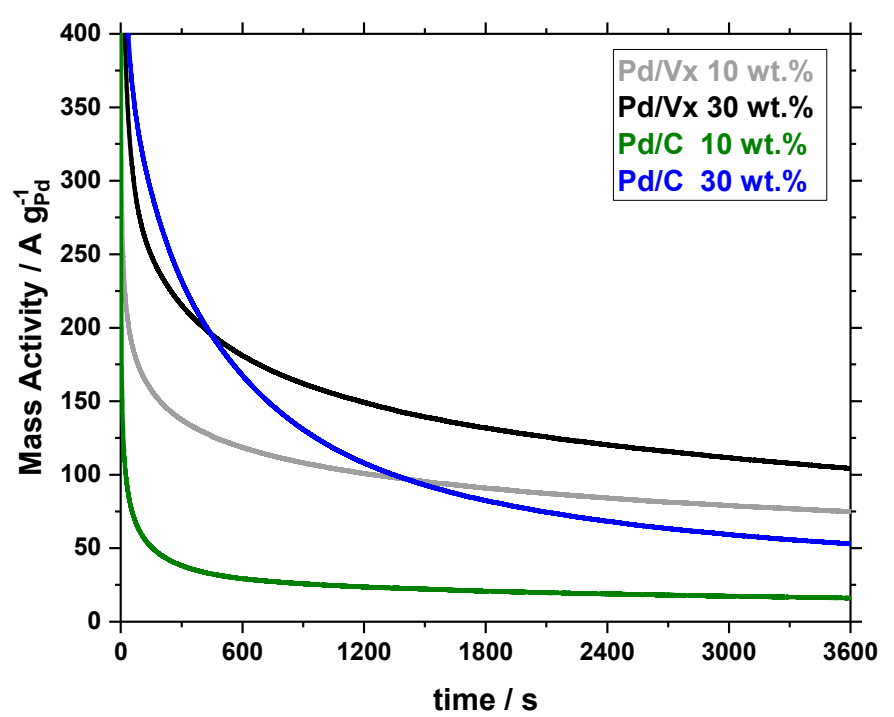

Figure 3. Examples of stability measurements showing the mass activity as a function of time for the different catalysts, as indicated. The mass activity is estimated based on the initial mass of Pd. Chronoamperometry was performed at $0.71 \mathrm{~V}$ vs. RHE in $1 \mathrm{M}$ ethanol in $1 \mathrm{M} \mathrm{KOH}$ in presence of argon for $3600 \mathrm{~s}$. The nominal Pd loading on the electrode is $9 \mu \mathrm{g}$.

In order to gain more insight into the degradation mechanism(s), further $\mathrm{CV}$ measurements were performed after the $\mathrm{CA}$; see Figure $2 \mathrm{~b}$. The current measured confirms that all catalysts are still active, since the typical shape of cyclic voltammograms for ethanol electro-oxidation by $\mathrm{Pd}$ is observed. The loss of activity over time in CA experiments can be addressed in the first place to the deactivation of the catalysts by poisoning of the Pd surface [50]. The NPs are further cleaned when CV is performed and so high (or even higher) mass activities are recovered.

\subsection{Post-Catalysis Characterization}

\subsubsection{Electro-Active Surface Estimation}

To get more insight into the possible deactivation mechanism(s) of the catalyst, an estimation of the final ECSA was performed by directly transferring the electrode tip from a solution containing ethanol to a solution without ethanol in alkaline water. During this transfer, several CV sweeps (typically ca. 10-20) were necessary to remove the oxidation current from the remaining ethanol. To best compare the catalysts in a unified protocol, a CA step of $5 \mathrm{~min}$ was systematically performed to remove the residual amount of ethanol (see details in the Materials and Methods Section).

A clear trend is that for commercial catalysts, the ECSA after EOR is superior to the ECSA evaluated initially, as summarized in Table 1 and illustrated in Figure S2. This was observed for a total of 17 experiments out of 19 performed for a range of experimental conditions such as different ink composition, catalyst loading on the carbon support (10 or $30 \mathrm{wt} \%$ ), and different platinum loading on the electrode; see Tables S1 and S2. This suggests that upon CV and CA, the commercial catalysts get activated. In contrast, the as-prepared catalysts show consistently a decrease in ECSA (observed for 19 experiments out of 23). The decrease in ECSA can be ascribed to two main causes: (1) loss of NPs or (2) loss of NP surface e.g., by size increase. The loss of ECSA could also be accounted to poisoning of the surface. The latter is not likely to be the main reason, since several CV sweeps can help recovering the catalyst activity in a re-activation process to a level close to or higher than the activity observed before

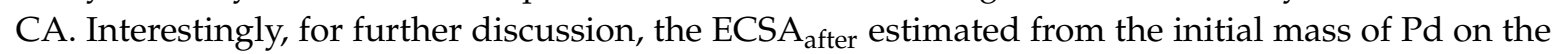
electrode is around $20-30 \mathrm{~m}^{2} \cdot \mathrm{g}^{-1}$ after chromoamperometric measurements for all catalysts. 


\subsubsection{Post-Mortem Transmission Electron Microscopy}

To complete this observation, post-mortem TEM analysis of the catalysts was performed by collecting the residual catalyst from the electrode tips after electrochemical characterization and testing. Figure 4 gathers the TEM micrographs for the catalyst after electrochemical characterization. For the home-made catalysts, a clear increase in the NP size is observed, and the NP diameter after electrocatalysis $\left(d_{\text {after }}\right)$ is now around $5.5 \mathrm{~nm}$; see Table 1 . This size increase to a similar value is in agreement with the decrease in ECSA and the relatively converging ECSA after values obtained. The loss of activity over time for the small size Pd catalyst $(<3 \mathrm{~nm})$ prepared here is attributed at least in part to a size increase of the NPs. The exact mechanism for the size increase is still to be clarified, but it could be Ostwald ripening or migration-coalescence [51]. For the commercial catalysts, a small size increase is observed, which is mainly attributed to the disappearance of the smallest NPs. The sample also showed more agglomeration of the NPs after electrochemical treatment; see Figure S4.
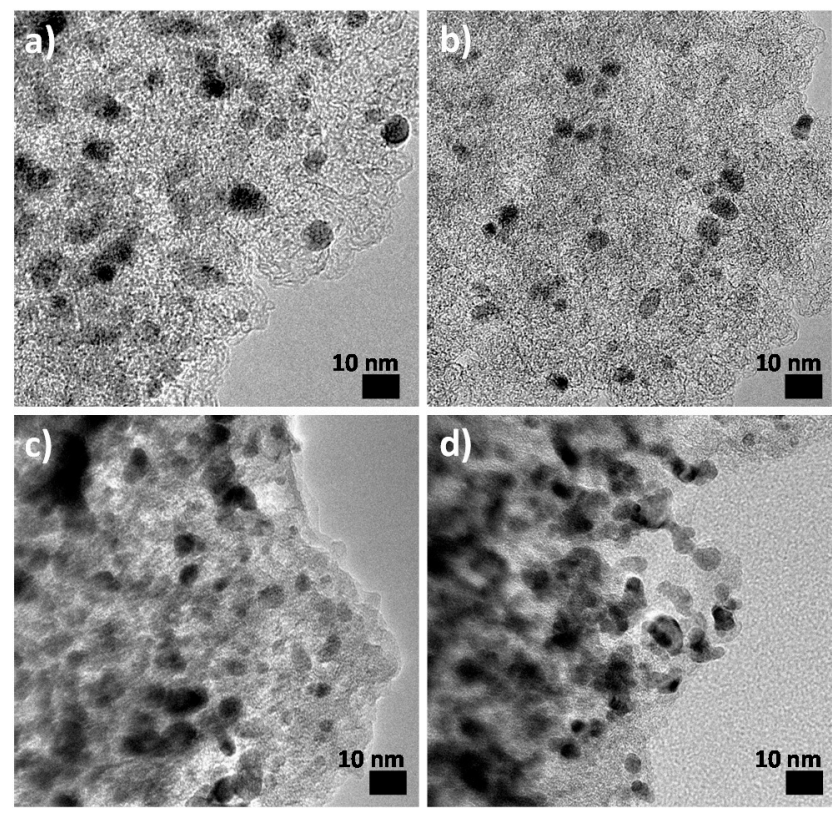

Figure 4. TEM micrographs of $\mathrm{Pd} / \mathrm{C}$ catalysts after electrochemical treatment for prepared $\mathrm{Pd} / \mathrm{Vx}$ (a) $10 \mathrm{wt} \%$ and (b) $30 \mathrm{wt} \%$ and commercially available Pd/C (c) $10 \mathrm{wt} \%$ and (d) $30 \mathrm{wt} \%$.

\section{Discussion}

The synthesized catalysts $\mathrm{Pd} / \mathrm{Vx} 10 \mathrm{wt} \%$ and $30 \mathrm{wt} \%$ prepared from surfactant-free sub $3 \mathrm{~nm} \mathrm{Pd}$ NPs show higher stability (higher activity maintained under 3600 s of CA at $0.71 \mathrm{~V}$ vs. RHE in $1 \mathrm{M}$ ethanol and $1 \mathrm{M} \mathrm{KOH}$ ) for the EOR compared to commercial catalysts with same Pd loading, as shown in Figure 3. This illustrates a first benefit of synthesized catalysts prepared by simple room temperature synthesis. We here compared home-made materials and commercial samples of the same metal and using the same electrochemical protocols to benchmark the Pd activity. This stresses a second benefit of the model system presented for comparative studies. It can be found in the literature reports where the "benchmark" is another metal similar to Pt [52], whereas it is known that Pt has a lower activity than Pd in alkaline conditions for ethanol oxidation [33]. It is here shown that using 10 or $30 \mathrm{wt} \%$ commercial $\mathrm{Pd} / \mathrm{C}$ may also not give the same mass activity. This highlights the need for careful selection of the benchmark to use (e.g., with different metal loading). Alternatively, the simple and fast synthesis we proposed can lead to a simple way to prepare benchmarks for Pd-based catalysts testing.

A final observation is that the losses of mass activity during EOR seem to have different origins depending on the system used. A loss of mass activity can be generally due to (1) poisoning of the catalyst surface, (2) loss of active surface area due to a size increase, or (3) loss of Pd atoms e.g., by dissolution. To ultimately address the contribution of Pd loss, further techniques such as post-mortem 
quantification of the catalyst loading on the electrode or a quantification of the Pd remaining in the electrolyte would be needed. However, such characterization [53,54] goes beyond the scope of the present study.

For $\mathrm{Pd} / \mathrm{C}$ commercial catalysts, the mass activity decrease during chronoamperometry experiments seems to results mainly from poisoning of the catalytic surface [55]. Indeed, an increase in the ECSA is observed over time. This suggests that even in the case of loss of material, the NPs are still active (if a loss of material occurs, the ECSA and mass activity which are mass-normalized metrics will be even higher than those estimated). TEM micrographs suggest that upon testing, the Pd/C $10 \mathrm{wt} \%$ sample may undergo a loss of Pd. However, at this low Pd loading on carbon, TEM is not suitable techniques to further conclude. Only an advanced techniques such as in-line ICP could give a firm answer to the degradation mechanism $[53,54]$.

For the synthesized as-prepared catalysts $\mathrm{Pd} / \mathrm{Vx}$, the loss of activity over time is less important than for the commercial catalysts, as shown in Figure 2. This can be explained by the initially high activity of the surfactant-free catalyst compensating a combination of surface poisoning and loss of active surface area. It is indeed clear from post-mortem TEM analysis, as shown in Figure 4, that the as-prepared NPs undergo a significant size increase. Here, we also attempted to characterize the ECSA after assessing the activity and stability of the catalysts. The size increase correlates well with the lower ECSAs measured after EOR. Therefore, it is remarkable that despite significant structural changes, the synthesized catalysts retain a relatively high activity.

Interestingly, the final size for all catalysts under the protocol selected here is around 5-7 nm, and the ECSA is around $20-30 \mathrm{~m}^{2} \cdot \mathrm{g}^{-1}$ in all cases. It was shown that the optimal size of Pt catalysts for the oxygen reduction, taking into account not only activity but also stability, is around $3 \mathrm{~nm}$. Therefore, an optimal NP catalyst size is not always the smallest size that can be achieved [56,57]. This result suggests that the optimal size for Pd NPs design may also not be the smallest possible (here, sub $3 \mathrm{~nm}$ ). Interestingly, the specific activity (SA) of the catalysts, i.e., the activity estimated per surface area of active $\mathrm{Pd}$, is higher for the prepared catalysts $\left(>3 \mathrm{~A} \cdot \mathrm{mPd}^{-2}\right)$ compared to commercial catalysts $\left(<3 \mathrm{~A} \cdot \mathrm{mPd}^{-2}\right)$ after chronoamperometry. This suggests that the prepared catalyst are intrinsically more active than their commercial counterparts are. The results also suggest that loading effects may play a role in the degradation mechanism and would gain to be investigated in studies where size and loading are independently controlled [58]. In this study, the loading was changed independently of the NP size, and the synthesis proposed is relevant for such future investigation. These results show the benefits of the room temperature synthesis to easily produce Pd NPs to be used as reference materials across future studies.

\section{Materials and Methods}

The overall workflow for the study is summarized in Figure S5.

\subsection{Chemicals}

All chemicals were used as received. $\mathrm{Pd}\left(\mathrm{NO}_{3}\right)_{2}(99.8 \%$, Alfa Aesar,); $\mathrm{NaOH}(98 \%$, Alfa Aesar); methanol ( $\geq 99.8 \%$, Sigma-Aldrich,); ethanol absolute (AnalaR Normapur, VWR,); water (Milli-Q, Millipore, resistivity $>18.2 \mathrm{M} \Omega \cdot \mathrm{cm}$, total organic carbon $<5 \mathrm{ppb}$ ); carbon support: Vulcan XC72R, Cabot Corporation, Brunauer-Emmett-Teller (BET) area: $235 \mathrm{~m}^{2} \cdot \mathrm{g}^{-1}$; Ar (99.999\%, Air Liquide,); Nafion ${ }^{\circledR} 10$ wt \% (Sigma Aldrich); Commercial Pd supported on carbon 10 wt \% and 30 wt \% (Sigma-Aldrich 205699 and 407306 catalogue number); $\mathrm{KOH} \cdot \mathrm{xH}_{2} \mathrm{O}\left(\geq 99.995 \%\right.$, Fluka), $\mathrm{HClO}_{4}(70 \%$, Suprapur ${ }^{\circledR}$, Merck,); $\mathrm{HCl}\left(37 \%\right.$, EMSURE ${ }^{\circledR}$ ACS, ISO, Reag. Ph Eur); $\mathrm{HNO}_{3}\left(67 \%\right.$, Normatom ${ }^{\circledR}$ VWR, $)$; $1000 \mathrm{ppb}$ Pt (ICP Standard, Pd, Lab support).

\subsection{Supported NP Synthesis}

In a container (A) (plastic centrifuge tube), a known mass of $\mathrm{Pd}\left(\mathrm{NO}_{3}\right)_{2}$ grains (ca. $4 \mathrm{mg}$ ) were placed together with a magnetic stirrer. In another container (B), the required amount of Vulcan to 
obtain a final $\mathrm{Pd} / \mathrm{C}$ weight ratio of $10 \mathrm{or} 30 \mathrm{wt} \%$ was prepared. To the latter container (B) was added the required volume of a $40 \mathrm{mM}$ alkaline $(\mathrm{NaOH})$ methanol solution so as to obtain a final concentration of $4 \mathrm{mM}$ of $\mathrm{Pd}\left(\mathrm{NO}_{3}\right)_{2}$ after mixing (A) and (B), as detailed below. The container (B) containing carbon and the alkaline alcohol was sonicated for $5 \mathrm{~min}$ (VWR ultrasonic cleaner, $35 \mathrm{kHz}, 160 \mathrm{~W}$ ) prior to be mixed with (A). Mixing (A) and (B) was performed so that the container (A) was placed on a magnetic stirrer (1000 rotation per minutes) and the mixture contained in (B) was added quickly in one single step. Then, the container was closed. The solutions were left under vigorous stirring for $3 \mathrm{~h}$.

\section{3. $P d / V x$ Ink Preparation}

The as-prepared solutions containing the $\mathrm{Pd} / \mathrm{Vx}$ were centrifuged for $5 \mathrm{~min}$ at a 2400 relative centrifugal force (4000 rotations per minute, Sigma 2-5). Then, the methanol was removed. Ca. $15 \mathrm{~mL}$ of methanol were added for washing, and the step washing/centrifugation was repeated 2 times in total. After removing the methanol, an acetone: $\mathrm{H}_{2} \mathrm{O}(3: 1 ; v: v)$ solution was added so that the volume was used to lead to a final nominal ink concentration of $1.0 \mathrm{mg}_{\mathrm{Pd}} \cdot \mathrm{mL}^{-1}$. Then, $100 \mu \mathrm{L}$ of the ink was mixed with $10 \mu \mathrm{L}$ of Nafion ${ }^{\circledR} 1 \%$ (obtained by dilution of the stock solution of Nafion ${ }^{\circledR}$ in MilliQ water). Then, the mixed solution was sonicated for $1 \mathrm{~min}$ (VWR ultrasonic cleaner, $35 \mathrm{kHz}, 160 \mathrm{~W}$ ). Every step involving pipetting a volume lower than $1 \mathrm{~mL}$ was performed with solution cooled down in an ice bath to prevent acetone evaporation. A similar procedure without washing steps was used for preparing $\mathrm{Pd} / \mathrm{C}$ inks.

Alternatively, twice the amount of Nafion ${ }^{\circledR}(20 \mu \mathrm{L})$ was used in the ink composition, but no significant influence on the catalysts properties could be observed. Using acid $(+10 \mu \mathrm{L})$ such as $0.1 \mathrm{M} \mathrm{HClO}_{4}$ in the ink composition also did not change the results. Different ink compositions were investigated: isopropanol, acetone: $\mathrm{H}_{2} \mathrm{O}(1: 1 ; v: v)$, ethanol: $\mathrm{H}_{2} \mathrm{O}(1: 1 ; v: v)$, methanol: $\mathrm{H}_{2} \mathrm{O}(1: 1 ; v: v)$, and $\mathrm{H}_{2} \mathrm{O}$. The most stable $\mathrm{Pd} / \mathrm{Vx}$ dispersions were obtained with acetone: $\mathrm{H}_{2} \mathrm{O}(3: 1 ; v: v)$ and so were studied in more detail.

\subsection{Electrochemistry}

\subsubsection{Electrode Preparation}

First, $10 \mu \mathrm{L}$ of the ink were deposited on a glassy carbon disc electrode tip ( $5 \mathrm{~mm}$ in diameter) polished to mirror finish using alumina paste (first $1.0 \mu \mathrm{m}$, then $0.3 \mu \mathrm{m}$ ), and clean ultrasonically in water. The drop was left to dry in a fume cupboard. The electrode geometrical surface area was $0.2 \mathrm{~cm}^{2}$. A summary of the different experiments performed is given in Table S1.

\subsubsection{Electrochemical Cell}

A Teflon cell was used. The modified glassy carbon disc electrode, carbon rod, and a saturated calomel electrode (SCE) were used as the working electrode, counter electrode, and reference electrode, respectively. All experiments were performed with argon bubbling in the electrolyte. The electrode was not rotated. All voltages are further expressed vs. the relative hydrogen electrode (RHE) using the formula $V$ vs. RHE $=V$ vs. SCE $+1.07 \mathrm{~V}$. The voltage of $0.71 \mathrm{~V}$ vs. RHE $(-0.36 \mathrm{~V}$ vs. SCE) for chronoamperometry was chosen as a voltage corresponding to the current density intercept of the forward and backward scan in CV. The voltage $0.77 \mathrm{~V}$ vs. RHE (-0.30 V vs. SCE) was chosen to compare results with Reference [59].

\subsubsection{Electrochemical Measurements}

The electrochemical assessments of the Pd NPs followed the sequence summarized in Table 2. To test the electrochemical properties of the $\mathrm{Pd} / \mathrm{Vx}$ and $\mathrm{Pd} / \mathrm{C}$ catalysts, different electrochemical treatments were performed on the same disc electrode tip. The mass activity was estimated based on ICP-MS mass measurements of the mother solution used for each of the 4 catalysts. 
Table 2. Electrochemical characterization protocol.

\begin{tabular}{cccc}
\hline Steps & Electrolyte & Conditions & Purpose \\
\hline 1 & $1 \mathrm{M} \mathrm{KOH}$ & CV-5 sweeps & ECSA before EOR \\
2 & $1 \mathrm{M} \mathrm{KOH}+1 \mathrm{M}$ ethanol & CV-10 sweeps & Mass Activity \\
3 & $1 \mathrm{M} \mathrm{KOH}+1 \mathrm{M}$ ethanol & CA-60 min & Mass Activity \\
4 & $1 \mathrm{M} \mathrm{KOH}+1 \mathrm{M}$ ethanol & $\mathrm{CV}-10$ sweeps & Mass Activity \\
5 & $1 \mathrm{M} \mathrm{KOH}$ & $\mathrm{CV}-5$ sweeps & - \\
6 & $1 \mathrm{M} \mathrm{KOH}$ & $\mathrm{CA}-5$ min & Cleaning \\
7 & $1 \mathrm{M} \mathrm{KOH}$ & $\mathrm{CV}-5$ sweeps & ECSA after EOR \\
\hline
\end{tabular}

* Cyclic voltammetry $(\mathrm{CV})$ sweeps were recorded at $50 \mathrm{mV} \cdot \mathrm{s}^{-1}$ between 0.27 and $1.27 \mathrm{~V} \mathrm{vs}$. RHE. Chronoamperometry (CA) was performed at $0.71 \mathrm{~V}$ vs. RHE.

\subsubsection{Electrochemically Active Surface Area (ECSA)}

The ECSAs of the Pd NPs were estimated by integration of the Pd oxide reduction peak from the 5 th scans recorded between 0.27 and $1.27 \mathrm{~V}$ vs. RHE at a scan rate of $50 \mathrm{mV} \cdot \mathrm{s}^{-1}$ in $1 \mathrm{M} \mathrm{KOH}$ using $424 \mu \mathrm{C} \cdot \mathrm{cm}^{-2}$ as a conversion factor [60].

\subsubsection{Cyclic Voltammetry (CV)}

The electrode is characterized by cycling between 0.27 and $1.27 \mathrm{~V}$ vs. RHE 10 times at a scan rate of $50 \mathrm{mV} \cdot \mathrm{s}^{-1}$ in $1 \mathrm{M} \mathrm{KOH}$ aqueous electrolyte (for ECSA measurements) or in a solution of $1 \mathrm{M}$ ethanol $+1 \mathrm{M} \mathrm{KOH}$ aqueous electrolyte for electrocatalytic measurements.

\subsubsection{Chronoamperometry (CA)}

For stability measurements, the electrode is characterized by holding the potential at $0.71 \mathrm{~V}$ vs. RHE in $1 \mathrm{M}$ ethanol $+1 \mathrm{M} \mathrm{KOH}$ aqueous electrolyte for $3600 \mathrm{~s}$. A chronoamperometry step for $5 \mathrm{~min}$ was also performed when the electrode was transferred from an electrolyte containing ethanol to an electrolyte not containing ethanol to remove the possible leftover ethanol on the electrode surface.

\subsection{TEM Characterization}

For TEM analysis, a JEOL 2100 microscope (Akishima, Tokyo, Japan) operated at $200 \mathrm{kV}$ was used. Size and morphologies were estimated by recording images at three different magnifications (at least $\times 100,000, \times 200,000, \times 300,000$ ) in at least three randomly selected areas. The samples were prepared for TEM analysis by dropping the solutions containing the $\mathrm{Pd} / \mathrm{Vx}$ or $\mathrm{Pd} / \mathrm{C}$ ink diluted by a factor ca. 50 in methanol on carbon-coated copper TEM grids (Quantifoil). The size analysis was performed by measuring the size at least 100 NPs using the ImageJ software. For characterization of the NPs after electrochemical treatment, Pd NPs supported on carbon were collected from the glassy carbon tip and re-dispersed in ethanol prior to deposition on a TEM grid.

\subsection{ICP-MS Measurements}

The metal loading and mass used for the different catalysts were analyzed by induced couple plasma mass spectrometry (ICP-MS). Samples were prepared by digesting the supported NPs with freshly prepared aqua regia $\left(37 \% \mathrm{HCl}\right.$ and $67 \% \mathrm{HNO}_{3}$ in a volume ratio 1:3) and left for digestion at 60 ${ }^{\circ} \mathrm{C}$ for $2 \mathrm{~h}$. Beware when using aqua regia to follow a careful safety procedure due to the strong acidity of the reaction mixture.

\section{Conclusions}

A simple room temperature synthesis method to obtain sub $3 \mathrm{~nm}$ surfactant-free Pd NPs on carbon was used to study the effect of loading and size by comparing synthesized and commercial catalysts for the ethanol oxidation reaction (EOR). The as-prepared Pd/Vx NPs show a more defined size and distribution over the support materials compared to the commercial catalysts. This leads to 
higher stability and long-term mass activity for the EOR in alkaline conditions, which is promising for direct ethanol fuel cells (DEFCs).

The comparison of new materials with a "standard" or "benchmark" is generally necessary in electrocatalysis, especially to compare mass activities and stability [61,62]. However, the comparison of commercial catalysts and synthesized catalysts can be challenging to fully understand the reasons for the activity loss over time. There is often little knowledge on the synthesis method of commercially available catalysts (e.g., production method, post-treatment, etc.). Comparing catalysts obtained from different suppliers/sources can complicate systematic comparison by impairing a clear understanding of the differences observed. This ultimately impairs a rational catalyst design. The mass activity loss of Pd NPs observed here over time can be related to different mechanisms: poisoning for the commercial catalysts versus poisoning together with marked size increase for the synthesized catalysts.

After electrochemical assessment, regardless of the NPs size and loading use, all the NPs reach a size of ca. 5-7 nm. The results indicate that the optimal size for Pd NPs design for the EOR may not be the smallest achievable size. The results finally stress the benefits of the simple synthesis method and approach we used that could be easily adapted to perform systematic studies of Pd NPs. This is relevant to study and optimize the electrocatalytic activity and stability for the EOR [33] but also other alcohols oxidation $[57,63,64]$ or alternative reactions where Pd is key [65]. The effect of support [66], loading [58], different electrochemical testing protocols including an "activation procedure" or longer tests [21,52], different electrolytes [67], the effect of adding surfactant to the catalyst [20], and ink composition [68] are all important parameters to understand in order to rationally design improved supported catalysts [37]. With the simple systems and approach presented, all these parameters can be systematically addressed and studied in greater detail.

Supplementary Materials: The following are available online at http://www.mdpi.com/2304-6740/8/11/59/s1, Figure S1: TEM and size distribution obtained from TEM analysis of different Pd NPs on carbon support with different metal loading, Figure S2: Cyclic voltammograms of the $\mathrm{Pd} / \mathrm{C}$ with different metal loading as indicated for ECSA determination in $1 \mathrm{M} \mathrm{KOH}$, Figure S3: Example of 1st to 10th cyclic voltammograms of $(a, b)$ commercial $30 \mathrm{wt} \% \mathrm{Pd} / \mathrm{C}$ (a) before and (b) after CA, (c,d) home-made $30 \mathrm{wt} \% \mathrm{Pd} / \mathrm{Vx}$ (c) before and (d) after CA at $0.71 \mathrm{~V}$ vs. RHE, Figure S4: TEM micrographs of commercial Pd/C $(a, b)$ before and $(c, d)$ after electrochemical treatment for commercial samples with $(\mathrm{a}, \mathrm{c}) 10 \mathrm{wt} \%$ and $(\mathrm{b}, \mathrm{d}) 30 \mathrm{wt} \%$, Figure S5: Work flow for catalyst synthesis, electrochemical evaluation, and post-mortem characterization, Table S1: Samples used for averaged electrochemical values reported, Table S2: Equivalent of Table 1 considering only the samples in gray in Table S1.

Author Contributions: Conceptualization, J.Q.; methodology, J.Q. and M.E.-E.; formal analysis, O.A.H.S.; investigation, O.A.H.S.; resources, M.E.-E.; writing—original draft preparation, O.A.H.S. and J.Q.; writing-review and editing, J.Q. and M.E.-E.; visualization, O.A.H.S. and J.Q.; supervision, J.Q. and M.E.-E. All authors have read and agreed to the published version of the manuscript.

Funding: J.Q. has received funding from the European Union's Horizon 2020 research and innovation programme under the Marie Skłodowska-Curie grant agreement No 703366 (SELECTRON). M.E.-E. gratefully acknowledges the Villum Foundation for the Award of a Villum Young Investigator Grant (Project Number: 19142).

Acknowledgments: S.B. Simonsen and L. Theil Kuhn, Technical University of Denmark, Denmark, are thanked for access to TEM facilities. J. McAnulty, Technical University of Denmark is thanked for access to ICP-MS and her help to perform measurements.

Conflicts of Interest: The authors declare no conflict of interest. The funders had no role in the design of the study; in the collection, analyses, or interpretation of data; in the writing of the manuscript, or in the decision to publish the results.

\section{References}

1. Witte, P.T.; Berben, P.H.; Boland, S.; Boymans, E.H.; Vogt, D.; Geus, J.W.; Donkervoort, J.G. BASF NanoSelect (TM) Technology: Innovative Supported Pd- and Pt-based Catalysts for Selective Hydrogenation Reactions. Top. Catal. 2012, 55, 505-511. [CrossRef]

2. Quinson, J.; Neumann, S.; Wannmacher, T.; Kacenauskaite, L.; Inaba, M.; Bucher, J.; Bizzotto, F.; Simonsen, S.B.; Kuhn, L.T.; Bujak, D.; et al. Colloids for Catalysts: A Concept for the Preparation of Superior Catalysts of Industrial Relevance. Angew. Chem.-Int. Ed. 2018, 57, 12338-12341. [CrossRef] 
3. Escudero-Escribano, M.; Malacrida, P.; Hansen, M.H.; Vej-Hansen, U.G.; Velazquez-Palenzuela, A.; Tripkovic, V.; Schiotz, J.; Rossmeisl, J.; Stephens, I.E.L.; Chorkendorff, I. Tuning the activity of Pt alloy electrocatalysts by means of the lanthanide contraction. Science 2016, 352, 73-76. [CrossRef] [PubMed]

4. Escudero-Escribano, M.; Jensen, K.D.; Jensen, A.W. Recent advances in bimetallic electrocatalysts for oxygen reduction: Design principles, structure-function relations and active phase elucidation. Curr. Opin. Electrochem. 2018, 8, 135-146. [CrossRef]

5. Pollet, B.G.; Kocha, S.S.; Staffell, I. Current status of automotive fuel cells for sustainable transport. Curr. Opin. Electrochem. 2019, 16, 90-95. [CrossRef]

6. Pedone, D.; Moglianetti, M.; De Luca, E.; Bardi, G.; Pompa, P.P. Platinum nanoparticles in nanobiomedicine. Chem. Soc. Rev. 2017, 46, 4951-4975. [CrossRef] [PubMed]

7. Rai, M.; Ingle, A.P.; Birla, S.; Yadav, A.; Dos Santos, C.A. Strategic role of selected noble metal nanoparticles in medicine. Crit. Rev. Microbiol. 2016, 42, 696-719. [CrossRef] [PubMed]

8. Wang, Q.Y.; Zhang, C.L.; Shi, L.; Zeng, G.F.; Zhang, H.; Li, S.G.; Wu, P.; Zhang, Y.L.; Fan, Y.Q.; Liu, G.J.; et al. Ultralow Pt Catalyst for Formaldehyde Removal: The Determinant Role of Support. Iscience 2018, 9, 487-501. [CrossRef]

9. Pradeep, T. Noble metal nanoparticles for water purification: A critical review. Thin Solid Film. 2009, 517, 6441-6478. [CrossRef]

10. Vesborg, P.C.K.; Jaramillo, T.F. Addressing the terawatt challenge: Scalability in the supply of chemical elements for renewable energy. Rsc. Adv. 2012, 2, 7933-7947. [CrossRef]

11. Losch, P.; Huang, W.X.; Goodman, E.D.; Wrasman, C.J.; Holm, A.; Riscoe, A.R.; Schwalbe, J.A.; Cargnello, M. Colloidal nanocrystals for heterogeneous catalysis. Nano Today 2019, 24, 15-47. [CrossRef]

12. Fievet, F.; Ammar-Merah, S.; Brayner, R.; Chau, F.; Giraud, M.; Mammeri, F.; Peron, J.; Piquemal, J.Y.; Sicard, L.; Viau, G. The polyol process: A unique method for easy access to metal nanoparticles with tailored sizes, shapes and compositions. Chem. Soc. Rev. 2018, 47, 5187-5233. [CrossRef] [PubMed]

13. El Amri, N.; Roger, K. Polyvinylpyrrolidone (PVP) impurities drastically impact the outcome of nanoparticle syntheses. J. Colloid Interface Sci. 2020, 576, 435-443. [CrossRef]

14. Liz-Marzan, L.M.; Kagan, C.R.; Millstone, J.E. Reproducibility in Nanocrystal Synthesis? Watch Out for Impurities! ACS Nano 2020, 14, 6359-6361. [CrossRef] [PubMed]

15. Cargnello, M.; Chen, C.; Diroll, B.T.; Doan-Nguyen, V.V.T.; Gorte, R.J.; Murray, C.B. Efficient Removal of Organic Ligands from Supported Nanocrystals by Fast Thermal Annealing Enables Catalytic Studies on Well-Defined Active Phases. J. Am. Chem. Soc. 2015, 137, 6906-6911. [CrossRef] [PubMed]

16. Niu, Z.Q.; Li, Y.D. Removal and Utilization of Capping Agents in Nanocatalysis. Chem. Mater. 2014, 26, 72-83. [CrossRef]

17. Li, D.G.; Wang, C.; Tripkovic, D.; Sun, S.H.; Markovic, N.M.; Stamenkovic, V.R. Surfactant Removal for Colloidal Nanoparticles from Solution Synthesis: The Effect on Catalytic Performance. ACS Catal. 2012, 2, 1358-1362. [CrossRef]

18. Huang, W.X.; Hua, Q.; Cao, T. Influence and Removal of Capping Ligands on Catalytic Colloidal Nanoparticles. Catal. Lett. 2014, 144, 1355-1369. [CrossRef]

19. Zhang, S.; Jiang, B.; Jiang, K.; Cai, W.-B. Surfactant-Free Synthesis of Carbon-Supported Palladium Nanoparticles and Size-Dependent Hydrogen Production from Formic Acid-Formate Solution. ACS Appl. Mater. Interfaces 2017, 9, 24678-24687. [CrossRef]

20. Yin, Y.R.; Ma, N.; Xue, J.; Wang, G.Q.; Liu, S.B.; Li, H.L.; Guo, P.Z. Insights into the Role of Poly(vinylpyrrolidone) in the Synthesis of Palladium Nanoparticles and Their Electrocatalytic Properties. Langmuir 2019, 35, 787-795. [CrossRef]

21. Quinson, J.; Simonsen, S.B.; Theil Kuhn, L.; Kunz, S.; Arenz, M. Size effect studies in catalysis: A simple surfactant-free synthesis of sub $3 \mathrm{~nm}$ Pd nanocatalysts supported on carbon. RSC Adv. 2018, 8, 33794-33797. [CrossRef]

22. Nasrollahzadeh, M.; Sajjadi, M.; Shokouhimehr, M.; Varma, R.S. Recent developments in palladium (nano)catalysts supported on polymers for selective and sustainable oxidation processes. Coord. Chem. Rev. 2019, 397, 54-75. [CrossRef] 
23. Monyoncho, E.A.; Steinmann, S.N.; Michel, C.; Baranova, E.A.; Woo, T.K.; Sautet, P. Ethanol Electro-oxidation on Palladium Revisited Using Polarization Modulation Infrared Reflection Absorption Spectroscopy (PM-IRRAS) and Density Functional Theory (DFT): Why Is It Difficult To Break the C-C Bond? ACS Catal. 2016, 6, 4894-4906. [CrossRef]

24. Bai, J.; Liu, D.Y.; Yang, J.; Chen, Y. Nanocatalysts for Electrocatalytic Oxidation of Ethanol. ChemSusChem 2019, 12, 2117-2132. [CrossRef]

25. Yao, C.X.; Zhang, Q.; Su, Y.; Xu, L.J.; Wang, H.; Liu, J.L.; Hou, S.F. Palladium Nanoparticles Encapsulated into Hollow N-Doped Graphene Microspheres as Electrocatalyst for Ethanol Oxidation Reaction. ACS Appl. Nano Mater. 2019, 2, 1898-1908. [CrossRef]

26. Jensen, K.D.; Tymoczko, J.; Rossmeisl, J.; Bandarenka, A.S.; Chorkendorff, I.; Escudero-Escribano, M.; Stephens, I.E.L. Elucidation of the Oxygen Reduction Volcano in Alkaline Media using a Copper-Platinum(111) Alloy. Angew. Chem. -Int. Ed. 2018, 57, 2800-2805. [CrossRef]

27. Xu, C.; Cheng, L.; Shen, P.; Liu, Y. Methanol and ethanol electrooxidation on Pt and Pd supported on carbon microspheres in alkaline media. Electrochem. Commun. 2007, 9, 997-1001. [CrossRef]

28. An, L.; Zhao, T.S.; Li, Y.S. Carbon-neutral sustainable energy technology: Direct ethanol fuel cells. Renew. Sustain. Energy Rev. 2015, 50, 1462-1468. [CrossRef]

29. Lai, S.C.S.; Kleijn, S.E.F.; Ozturk, F.T.Z.; Vellinga, V.C.V.; Koning, J.; Rodriguez, P.; Koper, M.T.M. Effects of electrolyte $\mathrm{pH}$ and composition on the ethanol electro-oxidation reaction. Catal. Today 2010, 154, $92-104$. [CrossRef]

30. Guo, J.S.; Chen, R.R.; Zhu, F.H.; Sun, S.G.; Villullas, H.M. New understandings of ethanol oxidation reaction mechanism on $\mathrm{Pd} / \mathrm{C}$ and $\mathrm{Pd}_{2} \mathrm{Ru} / \mathrm{C}$ catalysts in alkaline direct ethanol fuel cells. Appl. Catal. B-Environ. 2018, 224, 602-611. [CrossRef]

31. Badwal, S.P.S.; Giddey, S.; Kulkarni, A.; Goel, J.; Basu, S. Direct ethanol fuel cells for transport and stationary applications-A comprehensive review. Appl. Energy 2015, 145, 80-103. [CrossRef]

32. Varcoe, J.R.; Atanassov, P.; Dekel, D.R.; Herring, A.M.; Hickner, M.A.; Kohl, P.A.; Kucernak, A.R.; Mustain, W.E.; Nijmeijer, K.; Scott, K.; et al. Anion-exchange membranes in electrochemical energy systems. Energy Environ. Sci. 2014, 7, 3135-3191. [CrossRef]

33. Ma, L.; Chu, D.; Chen, R.R. Comparison of ethanol electro-oxidation on $\mathrm{Pt} / \mathrm{C}$ and $\mathrm{Pd} / \mathrm{C}$ catalysts in alkaline media. Int. J. Hydrog. Energy 2012, 37, 11185-11194. [CrossRef]

34. Bianchini, C.; Shen, P.K. Palladium-Based Electrocatalysts for Alcohol Oxidation in Half Cells and in Direct Alcohol Fuel Cells. Chem. Rev. 2009, 109, 4183-4206. [CrossRef]

35. Wang, Y.; Zou, S.Z.; Cai, W.B. Recent Advances on Electro-Oxidation of Ethanol on Pt- and Pd-Based Catalysts: From Reaction Mechanisms to Catalytic Materials. Catalysts 2015, 5, 1507-1534. [CrossRef]

36. Adishev, A.; Arrigo, R.; Baletto, F.; Bordet, A.; Bukhtiyarov, V.; Carosso, M.; Catlow, R.; Conway, M.; Davies, J.; Davies, P.; et al. Control of catalytic nanoparticle synthesis: General discussion. Faraday Discuss. 2018, 208, 471-495. [CrossRef]

37. Quinson, J.; Arenz, M. The toolbox concept for the synthesis of surfactant-free colloidal nanoparticles as electrocatalysts. ECS Trans. 2020, 97, 443-455. [CrossRef]

38. Bligaard, T.; Bullock, R.M.; Campbell, C.T.; Chen, J.G.G.; Gates, B.C.; Gorte, R.J.; Jones, C.W.; Jones, W.D.; Kitchin, J.R.; Scott, S.L. Toward Benchmarking in Catalysis Science: Best Practices, Challenges, and Opportunities. ACS Catal. 2016, 6, 2590-2602. [CrossRef]

39. Wen, C.N.; Li, Z.P.; Cao, C.Y.; Wang, Y.Q.; Guo, P.Z.; Zhao, X.S. Structural evolution of palladium nanoparticles and their electrocatalytic activity toward ethanol oxidation in alkaline solution. RSC Adv. 2016, 6, 91991-91998. [CrossRef]

40. Ma, X.-Y.; Chen, Y.; Wang, H.; Li, Q.-X.; Lin, W.-F.; Cai, W.-B. Electrocatalytic oxidation of ethanol and ethylene glycol on cubic, octahedral and rhombic dodecahedral palladium nanocrystals. Chem. Commun. 2018, 54, 2562-2565. [CrossRef]

41. Yang, H.; Zhang, X.; Zou, H.; Yu, Z.; Li, S.; Sun, J.; Chen, S.; Jin, J.; Ma, J. Palladium Nanoparticles Anchored on Three-Dimensional Nitrogen-Doped Carbon Nanotubes as a Robust Electrocatalyst for Ethanol Oxidation. ACS Sustain. Chem. Eng. 2018, 6, 7918-7923. [CrossRef]

42. Kaedi, F.; Yavari, Z.; Asmaei, M.; Abbasian, A.R.; Noroozifar, M. Ethanol electrooxidation on high-performance mesoporous ZnFe2O4-supported palladium nanoparticles. New J. Chem. 2019, 43, 3884-3890. [CrossRef] 
43. Ma, N.; Liu, X.H.; Yang, Z.Q.; Tai, G.J.; Yin, Y.R.; Liu, S.B.; Li, H.L.; Guo, P.Z.; Zhao, X.S. Carrageenan Asissted Synthesis of Palladium Nanoflowers and Their Electrocatalytic Activity toward Ethanol. ACS Sustain. Chem. Eng. 2018, 6, 1133-1140. [CrossRef]

44. Chen, Y.J.; Chen, Y.R.; Chiang, C.H.; Tung, K.L.; Yeh, T.K.; Tuan, H.Y. Monodisperse ordered indium-palladium nanoparticles: Synthesis and role of indium for boosting superior electrocatalytic activity for ethanol oxidation reaction. Nanoscale 2019, 11, 3336-3343. [CrossRef]

45. Su, Y.; Yao, C.X.; Zhan, Q.; Xu, L.J.; Wang, H.; Liu, J.L.; Hou, S.F. Palladium Nanoparticles Supported on B-Doped Carbon Nanocage as Electrocatalyst toward Ethanol Oxidation Reaction. ChemElectroChem 2019, 6, 5211-5219. [CrossRef]

46. Zhang, L.J.; Xia, D.G. Electrocatalytic activity of ordered intermetallic PtSb for methanol electro-oxidation. Appl. Surf. Sci. 2006, 252, 2191-2195. [CrossRef]

47. Manoharan, R.; Goodenough, J.B. Methanol oxidation in acid on ordered NiTi. J. Mater. Chem. 1992, 2, 875-887. [CrossRef]

48. Cuesta, A.; Escudero, M.; Lanova, B.; Baltruschat, H. Cyclic Voltammetry, FTIRS, and DEMS Study of the Electrooxidation of Carbon Monoxide, Formic Acid, and Methanol on Cyanide-Modified Pt(111) Electrodes. Langmuir 2009, 25, 6500-6507. [CrossRef]

49. Chen, L.; Lu, L.; Zhu, H.; Chen, Y.; Huang, Y.; Li, Y.; Wang, L. Improved ethanol electrooxidation performance by shortening Pd-Ni active site distance in Pd-Ni-P nanocatalysts. Nat. Commun. 2017, 8. [CrossRef]

50. Wu, Z.P.; Miao, B.; Hopkins, E.; Park, K.; Chen, Y.F.; Jiang, H.X.; Zhang, M.H.; Zhong, C.J.; Wang, L.C. Poisonous Species in Complete Ethanol Oxidation Reaction on Palladium Catalysts. J. Phys. Chem. C 2019, 123, 20853-20868. [CrossRef]

51. Meier, J.C.; Galeano, C.; Katsounaros, I.; Topalov, A.A.; Kostka, A.; Schuth, F.; Mayrhofer, K.J.J. Degradation Mechanisms of Pt/C Fuel Cell Catalysts under Simulated Start-Stop Conditions. ACS Catal. 2012, 2, 832-843. [CrossRef]

52. Begum, H.; Ahmed, M.S.; Jeon, S. Highly Efficient Dual Active Palladium Nanonetwork Electrocatalyst for Ethanol Oxidation and Hydrogen Evolution. ACS Appl. Mater. Interfaces 2017, 9, 39303-39311. [CrossRef] [PubMed]

53. Jovanovic, P.; Ruiz-Zepeda, F.; Sala, M.; Hodnik, N. Atomic Scale Insights into Electrochemical Dissolution of Janus Pt-SnO 2 Nanoparticles in the Presence of Ethanol in Acidic Media: An IL-STEM and EFC-ICP-MS Study. J. Phys. Chem. C 2018, 122, 10050-10058. [CrossRef]

54. Kasian, O.; Simon, G.; Mayrhofer, K.J.J.; Cherevko, S. Electrochemical On-line ICP-MS in Electrocatalysis Research. Chem. Rec. 2018, 19, 2130-2142. [CrossRef]

55. Meng, H.; Zeng, D.; Xie, F. Recent Development of Pd-Based Electrocatalysts for Proton Exchange Membrane Fuel Cells. Catalysts 2015, 5, 1221-1274. [CrossRef]

56. Antolini, E. Structural parameters of supported fuel cell catalysts: The effect of particle size, inter-particle distance and metal loading on catalytic activity and fuel cell performance. Appl. Catal. B Environ. 2016, 181, 298-313. [CrossRef]

57. Perez-Alonso, F.J.; McCarthy, D.N.; Nierhoff, A.; Hernandez-Fernandez, P.; Strebel, C.; Stephens, I.E.L.; Nielsen, J.H.; Chorkendorff, I. The Effect of Size on the Oxygen Electroreduction Activity of Mass-Selected Platinum Nanoparticles. Angew. Chem. Int. Ed. 2012, 51, 4641-4643. [CrossRef]

58. Perez, J.; Paganin, V.A.; Antolini, E. Particle size effect for ethanol electro-oxidation on Pt/C catalysts in half-cell and in a single direct ethanol fuel cell. J. Electroanal. Chem. 2011, 654, 108-115. [CrossRef]

59. Qin, Y.H.; Yang, H.H.; Zhang, X.S.; Li, P.; Ma, C.A. Effect of carbon nanofibers microstructure on electrocatalytic activities of Pd electrocatalysts for ethanol oxidation in alkaline medium. Int. J. Hydrogen. Energy 2010, 35, 7667-7674. [CrossRef]

60. Lukaszewski, M.; Soszko, M.; Czerwinski, A. Electrochemical Methods of Real Surface Area Determination of Noble Metal Electrodes-An Overview. Int. J. Electrochem. Sci. 2016, 11, 4442-4469. [CrossRef]

61. Pedersen, C.M.; Escudero-Escribano, M.; Velazquez-Palenzuela, A.; Christensen, L.H.; Chorkendorff, I.; Stephens, I.E.L. Benchmarking Pt-based electrocatalysts for low temperature fuel cell reactions with the rotating disk electrode: Oxygen reduction and hydrogen oxidation in the presence of $\mathrm{CO}$ (review article). Electrochim. Acta 2015, 179, 647-657. [CrossRef] 
62. Wei, C.; Rao, R.R.; Peng, J.Y.; Huang, B.T.; Stephens, I.E.L.; Risch, M.; Xu, Z.C.J.; Shao-Horn, Y. Recommended Practices and Benchmark Activity for Hydrogen and Oxygen Electrocatalysis in Water Splitting and Fuel Cells. Adv. Mater. 2019, 31. [CrossRef] [PubMed]

63. Davi, M.; Kessler, D.; Slabon, A. Electrochemical oxidation of methanol and ethanol on two-dimensional self-assembled palladium nanocrystal arrays. Thin Solid Film. 2016, 615, 221-225. [CrossRef]

64. He, Y.; Yang, P.; Fan, J.; Liu, Y.; Du, Y.; Feng, J.; Fan, F.; Li, D. Facile and surfactant-free synthesis of supported Pd nanoparticles on hydrotalcite for oxidation of benzyl alcohol. RSC Adv. 2015, 5, 74907-74915. [CrossRef]

65. Zhu, Q.L.; Tsumori, N.; Xu, Q. Immobilizing Extremely Catalytically Active Palladium Nanoparticles to Carbon Nanospheres: A Weakly-Capping Growth Approach. J. Am. Chem. Soc. 2015, 137, 11743-11748. [CrossRef] [PubMed]

66. Yang, Z.-R.; Wang, S.-Q.; Wang, J.; Zhou, A.-J.; Xu, C.-W. Pd supported on carbon containing nickel, nitrogen and sulfur for ethanol electrooxidation. Sci. Rep. 2017, 7. [CrossRef] [PubMed]

67. Arminio-Ravelo, J.A.; Jensen, A.W.; Jensen, K.D.; Quinson, J.; Escudero-Escribano, M. Electrolyte effects on the electrocatalytic performance of iridium-based nanoparticles for oxygen evolution in rotating disc electrodes. Chem. Phys. Chem. 2019, 20, 2956-2963. [CrossRef] [PubMed]

68. Inaba, M.; Quinson, J.; Arenz, M. pH matters: The influence of the catalyst ink on the oxygen reduction activity determined in thin film rotating disk electrode measurements. J. Power Sources 2017, 353, $19-27$. [CrossRef]

Publisher's Note: MDPI stays neutral with regard to jurisdictional claims in published maps and institutional affiliations.

(C) 2020 by the authors. Licensee MDPI, Basel, Switzerland. This article is an open access article distributed under the terms and conditions of the Creative Commons Attribution (CC BY) license (http://creativecommons.org/licenses/by/4.0/). 